\title{
COMMENTARY: The productivity of variability: an agroecological hypothesis
}

\author{
Michael M. Bell*, Alexandra Lyon, Claudio Gratton and Randall Jackson \\ University of Wisconsin Agroecology Program, Madison, WI 53706-1299, USA
}

\begin{abstract}
Most agronomic research seeks to limit the variability of productivity, offering universal 'recipe knowledge' that attempts to overwhelm contextual differences. Based on participatory research with a group of eight graziers in Wisconsin, we present the counter hypothesis that the productivity of variability is a key principle of agroecology. Contextual variability across space and time presents farmers with productive opportunities. Appreciating these contextual possibilities offers a universal principle that is not also a recipe.
\end{abstract}

Q1

Keywords:

For the last several years, we have been working with graziers in Wisconsin in the American Midwest to understand the ecological dynamics of managed grazing farming systems. In good scientific fashion, we first established an array of randomized field plots on a university research farm, comparing four management approaches: managed grazing, continuous grazing, mechanical harvesting and land set-aside. Then we worked with eight graziers to establish a system of on-farm trials that enabled us to measure results in real-life situations. Through this combination of manipulative experiments and on-farm trials, we have been able to learn much about the sources of variation in grass-based agriculture in our region (Jackson et al., 2007). Understanding this variability should help us increase the productivity of grazing systems while retaining and enhancing environmental benefits.

This is all to the good. But after a series of conversations with the farmers who participated in the

*Corresponding author: Email: michaelbell@wisc.edu on-farm work, we are now asking ourselves if this form of agronomic thinking - the standard one of trying to understand the variability of productivity - puts the real agroecological question exactly backwards. What if the route to productivity in these systems is not to learn how to limit the inevitable vicissitudes in the productivity of any approach to farming but rather to increase the potential productivity that comes from variation itself? In this brief commentary, we would like to sketch out such a switch in paradigmatic focus from the variability of productivity to the productivity of variability.

\section{What farmers want from agroecologists}

Take a group of ecologists, one college of agriculture, and mix. Three of us (Bell, Gratton and Jackson) constitute the new 'agroecology cluster' in the College of Agriculture at the University of Wisconsin. As ecologists new to the study of 
agricultural production, our understanding of this recipe was that we should do what agricultural science has long done and figure out what conditions lead to the highest production so that all farmers can apply these conditions - whether mechanical, mineral, chemical or animal - to their own operations. But as ecologists we would consider factors and farming approaches that were beyond the traditional purview of agricultural research, such as how plant structure creates a series of microhabitats for arthropods which may in turn shape the flow of nutrients in the field. Any findings that boosted productivity could then be passed on to farmers to emulate. It was a recipe for how to produce recipes.

Indeed, as we have travelled our state talking to graziers we often heard from them that this was what they wanted from us. Like any group of farmers, they had puzzles and annoyances that confounded even the most successful of them. They wanted reliable ways to attain the outcomes they desired - routines of activity that allowed them to get through the day, the season and the year. This toolkit of repeatability is what the phenomenologist Alfred Schutz (1962) liked to call 'recipe knowledge'. Although we doubt any of them have read Schutz, graziers themselves also called this kind of knowledge 'recipes' sometimes.

Graziers usually used the term 'recipes' disparagingly, however. For them, it described the knowledge practices of conventional agriculture, learned from the university and the corporation, and applied to the field - often literally applied in the form of the latest agricultural chemistry. For them, recipes meant farming by doing, not by thinking, and many graziers have long been wary of the university in part for this reason (Hasanein, Q2 1999). But, after all, producing recipes is what the university does, they seemed to reason, and they wanted to encourage our engagement with them after many years of relative neglect of their farming systems by university researchers. Plus there were those troubles and annoyances which maybe we really could help out with, even if they saw their approach to farming as something more than a process of recipe adoption.

So there was hope and unease on both sides. They hoped we might be helpful, but were uncertain whether what we could offer would be of much use. And we felt the same way. To be helpful seemed to be to provide recipes, but did such a role speak to our skills as ecologists, we wondered.

\section{What agroecologists can contribute to farmers}

Despite the unease, the project went ahead. We set up the mensurative experiments on the eight farms that served as counterparts to the manipulative experiments. We collected three seasons of samples. We ran the numbers. The farmers and researchers got to know each other and, we think, gained mutual respect through the participatory approach of the work.

But there was something that still felt vaguely unecological about the premise of the research, and both farmers and researchers seemed to sense it. For what agricultural recipe knowledge conventionally teaches are the universalistic practices of homogeneity - of how to overwhelm the variability of context with inputs of materials, machines, and muscles. Without homogeneity, universalism is not conventionally understood. Therefore, the universalism of the university teaches how, with enough baking soda and heat, the cake of agriculture will rise anywhere and everywhere. While ecology, on the other hand, proceeds from a reverence for context and the diversity of anywhere and everywhere such reverence implies.

This reverence is not irrelevant for the inescapable agricultural concern for production. Much ecological science finds, for example, a relationship between diversity and ecosystem productivity, across many ecosystems (Hooper et al., 2005; Loreau et al., 2001), including grasslands ecosystems (Guo, 2007). For example, one recent study found that diverse plant assemblages produce 1.7 times more biomass than monocultures, largely because of interspecies complementarity (Cardinale et al., 2007). Diversity depends in part upon the capacity of an ecosystem to provide a range of structural opportunities across space and time, two important dimensions of ecological variability. Graziers thus might adapt their practices across space, for example, by encouraging warm season grasses on drier slopes and cool season grasses on wetter ground. They may also adapt their practices across time, finding that in different seasons and 
different years the warm season grasses on the dry ground do better than the cool season grasses on the wet ground, giving stability to the farm's productive capacity over the longterm.

But even this is too prescriptive. What happens if a particular grazier does not have much wet ground, or conversely much dry ground? Moreover, the grain of variability, both social and ecological, that any farm has available to it is far too subtle for those on the outside, not intimately familiar with the land and its people, to comprehend its full productive possibilities. This is what we learned from our conversations with the farmers. It is ecological principles that graziers need from agroecological research, not ecological principals.

\section{Concluding thoughts}

Thus we propose the productivity of variability as a hypothesis for agroecology. We did not set out to measure this hypothesis in our research, but it could be done, and indeed is done, we believe, on graziers' farms all the time. Such research, whether practical or experimental, involves studying the effects of micro-level treatments that seek not to even out the hills and valleys of the unevenness of context across space and time - as is done with such spectacular commitment in 'precision agriculture', say, with its GPS marvels - but rather to see these unevennesses as opportunities for stable productivity over the longterm. Working with variation across space and time, rather than against it, seems to us the real meaning of the 'management' in 'managed grazing'.

There is a universalism in such a hypothesis, but of a very different sort than conventional agricultural recipe knowledge. The productivity of variability offers the universalism of principle, not of practice. It is a universalism that is, therefore, always based upon a reverence for context and thus appreciates the myriad parts of a whole without reductionism. It also provides a welcome space for the genius of the farmer and his or her contextual creativity.

In other words, there is a place in agroecological knowledge for universalism. But let this universalism be welcoming to the diversity of our contexts. Our principles should not overwhelm our practices. Nor should our practices overwhelm our principles. Finding this balance is ultimately the only productive thing to do.

\section{References}

Cardinale, B.J., Wright, J.P., Cadotte, M.W., Carroll, I. et al. (2007) Impacts of plant diversity on biomass production increase through time because of species complementarity. Proceedings of the National Academy of Sciences 104, 18123-18128.

Guo, Q. (2007) The diversity-biomass-productivity relationships in grassland management and restoration. Basic and Applied Ecology 8, 199-208.

Hassanein, N. (1999) Changing the way America Farms: Knowledge and Community in the Sustainable Agriculture Movement. Lincoln, Nebraska: University of Nebraska Press.

Hooper, D.U., Chapin, F.S., Ewel, J.J., Hector, A., Inchausti, P. et al. (2005) Effects of biodiversity on ecosystem functioning: A consensus of current knowledge, Ecological Monographs 75, 3-35.

Jackson, R.D., Bell, M.M. and Gratton, C. (2007) Assessing ecosystem variance at different scales to generalize about pasture management in southern Wisconsin. Agriculture, Ecosystems \& Environment 122, 471-478.

Loreau, M., Naeem, S., Inchausti, P., Bengtsson, J. et al. (2001) Biodiversity and ecosystem functioning: Current knowledge and future challenges. Science 294, 804.

Schutz, A. (1962) The Problem of Social Reality. The Hague: Martinus Nijhoff. 